\title{
EDITORIAL
}

\section{As reflexões sempre pertinentes e necessárias sobre as políticas educacionais...}

\section{Queremos Saber \\ Gilberto Gil}

Queremos saber

o que vão fazer

com as novas invenções

queremos notícia mais séria

sobre a descoberta da antimatéria

e suas implicações

na emancipação do homem

das grandes populações

homens pobres das cidades

das estepes, dos sertões

Queremos saber

quando vamos ter

raio laser mais barato

queremos de fato um relato

retrato mais sério

do mistério da luz

luz do disco-voador

pra iluminação do homem tão carente e sofredor

tão perdido na distância

da morada do Senhor

Queremos saber

queremos viver

confiantes no futuro

por isso de faz necessário

prever qual o itinerário da ilusão

a ilusão do poder

pois se foi permitido ao homem

tantas coisas conhecer

é melhor que todos saibam

o que pode acontecer

Queremos saber

queremos saber

todos queremos sabe

Esta edição é de suma relevância por dois motivos: o primeiro pelo empenho institucional em recuperar a periodicidade deste periódico; o segundo pelo fato de demarcar historicamente o processo de construção e aprovação do nosso Mestrado em Educação pela CAPES. E, consequentemente, pelo que passará a cumprir a revista pedagógica daqui por diante neste contexto de construção do Mestrado. Isto significa dizer que esse periódico, a partir desta edição, será o principal veículo 
de produção e veiculação do conhecimento na Pós-graduação e, também, de estímulo às pesquisas de Iniciação Científica no âmbito da formação em Pedagogia da Unochapecó.

Urge salientar que a busca por relação imbricada entre PósGraduação e Iniciação Científica sempre fez parte do projeto pedagógico da Unochapecó. Essa instituição vem contribuindo, há muitos anos, com a produção de conhecimento na iniciação científica e de pesquisas mais avançadas, desenvolvidas mais recentemente em nossos programas de pós-graduação stricto senso já implantados. Com a criação do Mestrado em Educação, ganhamos fôlego para recuperar a periodicidade da revista, consolidando, assim, uma mentalidade de pesquisa já instituída há 40 anos no cotidiano do Curso de Pedagogia.

Neste sentido, a revista tem como desafio seguir as trilhas das metas do nosso Projeto de Pós-Graduação Stricto Senso, em especial do Mestrado em Educação, qual seja: produzir e veicular conhecimento articulados aos problemas de relevância pública para a região oeste e entorno, assim como às tensas $\mathrm{e}$ significativas problemáticas educacionais de caráter nacional e internacional. Para tanto, urge estarmos atentos à produção do conhecimento em Educação, veiculada no Portal da CAPES, nos GT's da ANPED e nos periódicos em Educação que fazem parte do FEPAE/ANPED- Fórum de Editores de Periódicos da Área de Educação.

Diante dessas considerações iniciais, temos outro desafio para além de recuperar a periodicidade, que se consolida à medida que, fazendo um retrospecto histórico, reconhecemos o alto nível da revista, editada anteriormente sob a excelente coordenação da Profa. Maria dos Anjos Viela. Sob a sua tutela, a Revista Pedagógica, em edições anteriores, já começava mostrar sinais concretos de um projeto consolidado. Como, por exemplo, um Conselho Editorial de alto nível, que conta com 
a contribuição de pesquisadores nacionais e ${ }^{1}$ internacionais. Um exemplo empenho pode ser verificado já a partir do $n^{0} 13$ (2004), quando já começam a aparecer artigos publicados de pesquisadores de Portugal e Espanha e também passamos a contar com um corpo de pareceristas internacionais.

O esforço no trabalho de editoração pode ser constado pela última avaliação da CAPES em 2012. A revista recebeu a qualificação de B4, mesmo com a periodicidade interrompida, superando a nota anterior de B5. A meta da Profa. Maria dos Anjos já era, desde o período de 1999 a 2010, transformar a revista num periódico B2. Para tanto, buscou procedimentos para uma avaliação mais qualificada da revista, que incluíram as seguintes bases de indexação: MEC/CIBEC; Bibliografia Brasileira de Educação (BBE); IRESIE (Índice de Revistas de Educación Superior e Investigación Educativa - CESU-UNAM/ México); LATINDEX (Sistema Regional de Información em LÍNEA para Revistas Cientificas de América Latina, El Caribe, Espanha y Portugal).

Falemos agora da temática deste número: o dossiê políticas educacionais. Ele foi organizado pelo professor Ângelo Ricardo de Souza, integrante do programa de Pós-Graduação em Educação da Universidade do Paraná. O tema em pauta se constituiu nos últimos anos da agenda de debates acalorados acerca da crise do capital e, consequentemente, na Educação. Esse tema esteve e está muito presente, tanto no interior da comunidade acadêmica (GT's da ANPED), quanto na mídia e em outros setores da sociedade civil organizada: sindicatos e movimentos sociais. Este fato se deve à emergência teóricoprática e relevância social e política, diante dos profundos e radicais problemas da crise na educação brasileira. A atual

${ }^{1}$ Cf. CURY, Carlos Roberto Jamil. Educação e crise: Perspectivas para o Brasil. Revista Educação e Sociedade, Campinas, vol. 31, n. 113, p. 10891098, out.-dez. 2010. 
crise internacional do capitalismo neoliberal tem suscitado a retomada do papel do Estado e o questionamento da supremacia do mercado e seus agentes. Tal crise confirma o foco de algumas iniciativas legais e de alguns programas governamentais federais em favor da educação escolar pública no Brasil. Neste sentido, pode-se dizer que, mesmo considerando as criticas e as polêmicas, em torno das políticas educacionais de inclusão precárias e emergenciais, é importante reconhecer que há um grande número de leis e junto com elas os programas que se inclinam no sentido de uma maior presença do Estado no âmbito do direito à Educação.

As políticas educacionais e o seu estudo têm sido fortemente tensionados pela criação e divulgação de indicadores, uma vez que o contato dos pesquisadores e da sociedade em geral com tais dados permite maior reflexão sobre os resultados (e, antes, sobre os processos e sobre a condução) da própria ação do Estado no atendimento ao direito à educação. Isto é, quanto mais informações socializadas sobre a educação, potencialmente maior é o controle social. E, como os meios de comunicação têm especial apreço pelos dados quantitativos, a divulgação de dados desta natureza tem crescido e, com isto, potencialmente, é maior a condição de acompanhamento e controle social.

Por outro lado, especialmente no que tange à avaliação da (política de) educação, aqueles dados tendem a ser assimilados de maneira muito superficial, porque também é superficial a abordagem que os meios de comunicação dão a eles. Mas, mesmo assim, e como tais dados estão presentes na mídia generalizadamente, administradores públicos tendem a procurar as melhores, ou pelo menos, mais eficazes formas de se melhorar os indicadores. Esta é a questão de fundo tratada por Douglas D. Dittrich, no artigo Poder indutor do IDEB sobre as políticas educacionais do município de Curitiba, no qual o autor expressa os resultados de sua dissertação de mestrado (UFPR) e 
sistematiza três flagrantes da política educacional do município de Curitiba com potencial de gerar melhoria no IDEB dos anos iniciais do Ensino Fundamental, expressando o poder indutor do índice na geração de políticas educacionais. Tais flagrantes se traduzem, especialmente, na redefinição curricular sustentada nos descritores da Prova Brasil e da Provinha Brasil, as quais passaram a ser balizadas pelo objetivo de melhorar o IDEB do município para as séries iniciais do Ensino Fundamental.

Ainda sobre a avaliação educacional, o trabalho de Gabriela Schneider, denominado Outro olhar no sistema de avaliação: análise de questionário e outros dados sobre infraestrutura educacional tomam um aspecto pouco analisado na pesquisa em política educacional: a questão da infraestrutura e das condições materiais para o desenvolvimento da qualidade educacional. Neste artigo, a autora analisa os questionários de contexto do Sistema de Avaliação da Educação Brasileira - SAEB, do ano de 2005, e o da Prova Brasil de 2007, além de questões do Censo Escolar que se referem à infraestrutura escolar e a equipamentos e materiais pedagógicos. No artigo, a autora compara esses questionários com o Parecer 08/2010 do Conselho Nacional de Educação (Custo Aluno Qualidade Inicial), que apresenta parâmetros do que seriam as condições mínimas para o funcionamento das escolas. Tal cotejamento parte da ideia de que pode se utilizar a gama de dados que vem sendo produzido por meio dos sistemas de avaliação com a finalidade de melhorar as condições das escolas, uma vez que elas apresentam uma boa fotografia de tais condições, ainda que os instrumentos de coleta de dados das avaliações em questão apresentam alguns problemas. $\mathrm{O}$ escopo do artigo na discussão sobre a infraestrutura e condições materiais é importante, porque as escolas brasileiras, mesmo com fortes apelos e cobranças da sociedade, ainda não alcançaram uma igualdade nem nesse sentido e em sua maioria não possuem condições mínimas de 
qualidade.

$\mathrm{O}$ direito à educação demanda tais condições, uma vez que ele não se resume ao acesso à escola. Contudo, e mesmo assim, o acesso continua sendo elemento determinante para a qualidade educacional mesmo no ensino fundamental, tido como universalizado desde o final da década de 1990 no Brasil. Isto porque com as mudanças provocadas na legislação que constituiu o ensino fundamental de 9 anos, questões complexas surgiram como a idade de corte para o ingresso, organização dos tempos, avaliação, etc. O trabalho de Simone de Fátima Flach, denominado Influências das decisões judiciais na oferta da educação paranaense, trata desta questão. $\mathrm{O}$ artigo trata das principais discussões ocorridas no campo judicial e suas influências na oferta do ensino fundamental no contexto paranaense. A autora, analisando peças processuais, termos de ajustamento de conduta impostos ao poder executivo de alguns municípios e documentos de órgãos normativos dos sistemas de ensino, estadual e municipal, mostra que as decisões judiciais, além de causar desgastes sociais e políticos, influenciaram o planejamento político educacional sobre a oferta tanto do ensino fundamental quanto da educação infantil, a qual também foi impactada por aquela alteração legal.

Mas, as condições efetivas para o direito à educação são, no limite, proporcionais à prioridade financeira que se dá à educação. Nos anos de 1990, contribuiu muito para aquela universalização do ensino fundamental, a constituição da política de fundos. A criação do FUNDEF em 1996 (e início em 1998) foi decisiva para tanto. O artigo de Patrycia Byanca Furtado, produto de sua dissertação de mestrado defendida na UFSC, intitulado Vida e morte do FUNDEF, lida com todo o primeiro ciclo desta política, o FUNDEF, uma vez que ele foi encerrado em 2006 e em 2007 tivemos o início do FUNDEB, ampliando o alcance e as dimensões da política de fundos para 
a educação. Neste artigo, a autora analisa o FUNDEF tanto na concepção quanto na prática. A análise toma, essencialmente, a base legal e por concepção, a autora identifica a legislação de regência, enquanto que a prática se relaciona aos repertórios de decisões do Tribunal de Contas do Estado de Santa Catarina, no período de 1998-2006, centrando-se nos pareceres prévios das contas anualmente prestadas pelos Prefeitos Municipais e pelo Governador do Estado. O texto, com este percurso, identifica como a lei de regência se materializou nas decisões do TCE/SC ao longo da vigência do fundo.

As tomadas de decisões sobre os recursos financeiros e o uso e o controle social sobre tal uso destes recursos é que podem, na verdade, tornar a educação uma prioridade ou não. Sabidamente, as condições gerais para os trabalhadores docentes não são as mais adequadas, tanto em termos salariais, de carreira, de formação continuada, de condições materiais escolares para o exercício do seu ofício, quanto em relação às relações dos docentes com os dirigentes e com os processos de gestão escolar. Esta problemática (das relações dos docentes com a gestão escolar), comumentemente conhecida, é confrontada com dados de um survey realizado em 2009 e 2010, no artigo de Angelo Ricardo de Souza, "A perspectiva dos docentes paranaenses sobre a gestão da escola básica", cujo enfoque é considerar as distintas formas como os docentes da educação básica do estado do Paraná percebem as relações cotidianas com a gestão escolar. Diferentemente do que se possa imediatamente supor, as conclusões do trabalho mostram que os docentes têm uma leitura relativamente crítica da gestão escolar, mas tal capacidade de análise crítica está diretamente relacionada com a experiência na docência e na vida política. Assim, o autor mostra que a ampliação do controle social e da democratização da educação demanda uma formação política e o reconhecimento/fortalecimento da experiência dos docentes 
da educação básica.

Com isto, as investigações acerca das políticas educacionais têm, neste conjunto de textos, contribuições importantes para o desenvolvimento das reflexões críticas no campo de pesquisa, uma vez que, seja acerca das (políticas de) avaliações, seja sobre as condições materiais e de infraestrutura escolar, seja sobre o acesso a uma etapa de ensino, seja sobre as condições do financiamento da educação, ou seja, acerca da gestão escolar democrática, o panorama sobre o qual esses textos todos se desenvolvem toma o direito e a qualidade da educação como condição para todo cidadão brasileiro.

$\mathrm{Na}$ sessão de artigos, contamos com a contribuição multidisciplinar de autores da UFSC, UFMG, UDESC e outras universidades, além de estudiosos da Unochapecó. Os textos debatem questões como: juventude, trabalho e educação; as filosóficas, a formação e a emancipação humana; educação no campo; experiência formativa nos deslocamentos urbanos de jovens trabalhadores; família, escola, e psicologia escolar; formação, pesquisa e narração e outras.

A capa desta edição tem um significado muito especial para a Unochapecó e para Região Oeste. Trata-se produzido pelos estudantes do Curso de Licenciatura Intercultural Indígena da Unochapecó, no componente curricular de Leitura e produção de textos, professora Marcia Ione Surdi, em 2009/2. Esta obra de arte faz parte de uma narrativa que abarca elementos da cultura indígena, construída pelas alunas Kaingang: Elisandra Pedroso, Eva Feliciano, Neiva Lima dos Santos, Roseli dos Santos, Charlene Lopes e Ana Paula Narciso.

Para encerrar, queremos, em primeiro lugar, agradecer a todos os autores, colegas da Pós-Graduação(Mestrado) em Educação da Unochapecó, de outras universidades e do FEPAE/ANPED (Fórum de Editores de Periódicos da Educação), que vem se empenhando na recuperação da periodicidade desta revista, 
demonstrando, assim, uma postura solidária e colaborativa.; em segundo lugar fazer uma homenagem especial ao grande arquiteto Oscar Niemayer falecido recentemente.

Despedimos-nos com uma bela frase do Niemayer: você tem que pensar na política, a política é importante. Você tem que pensar na miséria. E, quando sentir que a coisa está ruim demais, e a esperança fugiu do coração dos homens, ai é revolução. (trecho do texto "Principais frases de Oscar Niemayer", publicado em 06/12/2012- www.uol.com.br). Boa leitura e até breve com os próximos números relativos às edições de 2011, 2012 e 2013.

Maurício Roberto da Silva Coordenador Editorial Ângelo Ricardo de Souza Programa de Pós-Graduação em Educação (PPGE) Universidade Federal do Paraná (UFPR) Editor Associado desta edição 